\title{
Those who can don't want to, and those who want to can't: eco-evolutionary constraints to decomposition explain soil carbon persistence
}

\author{
Mark Bonner ${ }^{1}$, Oskar Franklin ${ }^{2}$, Shun Hasegawa ${ }^{3}$, and Torgny Näsholm ${ }^{3}$ \\ ${ }^{1}$ Royal Melbourne Institute of Technology \\ 2iiasa \\ ${ }^{3}$ Sveriges Lantbruksuniversitet Fakulteten for Skogsvetenskap
}

February 17, 2021

\begin{abstract}
Reliable manipulation of soil organic matter (SOM) - a necessity for optimal land management - is constrained by our limited mechanistic understanding of SOM formation. Here we add to existing frameworks a novel mechanistic element that may underpin SOM dynamics, based on evolutionary-ecological rather than chemical or physical limitations to decomposition. We argue that decomposition of some substrates may be ecologically constrained in mycelial fungi, evolutionarily constrained in co-operating bacteria, and geometrically constrained in unicellular microbes. We describe and test a mathematical model based on our framework, providing a proof-of-concept that substrate can plausibly be spared decomposition and accumulate even when it is physically and chemically accessible. Our framework can explain a variety of SOM dynamics, including priming and the suppression of decomposition by nitrogen addition, as well as the typical composition of SOM. An augmented mechanistic framework for understanding SOM dynamics can help guide targeted empirical study, which in turn can contribute to more optimised land management.
\end{abstract}

Those who can don't want to, and those who want to can't: eco-evolutionary constraints to decomposition explain soil carbon persistence

Mark TL Bonner ${ }^{1,2^{*}}$, Oskar Franklin ${ }^{2,3}$, Shun Hasegawa ${ }^{2}$, and Torgny Näsholm²

${ }^{1}$ Applied Chemistry and Environmental Science, Royal Melbourne Institute of Technology (RMIT), Melbourne, Australia

${ }^{2}$ Department of Forest Ecology and Management, Swedish University of Agricultural Sciences (SLU), Umeå, Sweden

${ }^{3}$ International Institute for Applied Systems Analysis (IIASA), Laxenburg, Austria

*Corresponding author. Email: mark.bonner@uqconnect.edu.au; Tel.: +61 432 540 011; Main address: Applied Chemistry and Environmental Science, Royal Melbourne Institute of Technology, Melbourne, Australia

Running title: SOM persistence due to geometry of oxidation

Keywords: soil organic matter, bacteria, fungi, oxidative enzymes, microbial ecology, carbon and nitrogen stoichiometry

Word and figure counts: abstract $=156$ words; main text $=3258$ words; 1 table; 6 figures 
Statement of authorship: MB conceived of the concepts, helped design the model and wrote the manuscript; OF designed and implemented the model and wrote the model sections of the manuscript; SH \& TN helped refine the concepts, model, and manuscript.

Data accessibility statement: We confirm that, should the manuscript be accepted, the data supporting the results (detailed model outputs) will be archived in an appropriate public repository and the data DOI will be included at the end of the article.

\begin{abstract}
Reliable manipulation of soil organic matter (SOM) - a necessity for optimal land management - is constrained by our limited mechanistic understanding of SOM formation. Here we add to existing frameworks a novel mechanistic element that may underpin SOM dynamics, based on evolutionary-ecological rather than chemical or physical limitations to decomposition. We argue that decomposition of some substrates may be ecologically constrained in mycelial fungi, evolutionarily constrained in co-operating bacteria, and geometrically constrained in unicellular microbes. We describe and test a mathematical model based on our framework, providing a proof-of-concept that substrate can plausibly be spared decomposition and accumulate even when it is physically and chemically accessible. Our framework can explain a variety of SOM dynamics, including priming and the suppression of decomposition by nitrogen addition, as well as the typical composition of SOM. An augmented mechanistic framework for understanding SOM dynamics can help guide targeted empirical study, which in turn can contribute to more optimised land management.
\end{abstract}

\title{
Introduction
}

Soil organic matter (SOM) is pivotal to most of the soil functions that benefit human welfare, among other things supporting plant productivity, mitigating flooding and sequestering monumental quantities of carbon (Schmidt et al. 2011; Lal 2014), yet we lack a sufficiently rigorous mechanistic understanding of SOM formation and stabilisation to reliably guide land management practices towards SOM maximisation. Current conceptual models typically build on the premise that only physically or chemically unreachable substrates will ultimately be spared decomposition and thereby contribute to long-lived SOM. We modify this view with the premise that, in addition to the unreachable substrate, some reachable substrate can be spared decomposition for evolutionary-ecological reasons. Game-theoretically, the former premise derives from a scenario in which resource exploitation at the microbial community level emerges from positive-sum, co-operative games between microbial phenotypes (Table 1). We derive the second premise from allowing for competitive, often zero-sum games between phenotypes, which can undermine the return on investment for decomposition of certain substrates. For analogy, we consider a scenario in which a predator has exclusive ability to bring down a prey species but lacks the ability to restrain scavengers. The prey will be spared because its sole predator lacks incentive for its predation. In the following, we present a case and establish a mathematical model to demonstrate that for non-hydrolysable nitrogen-rich substrate (prey), precisely such an impasse can occur between cord-forming basidiomycete saprotrophic fungi (predator) and fast-growing opportunistic bacteria (scavengers).

\section{The concept}

The importance of geometry: nutrition

Like all heterotrophs, saprotrophic microbes require carbon $(\mathrm{C})$ and nitrogen $(\mathrm{N})$ in appropriate amounts from their food. A common calculation for the Threshold Elemental Ratio (TER) of substrate C:N, above which $\mathrm{N}$ is limiting and below which $\mathrm{C}$ is limiting, is

$\mathrm{TER}_{C: N}=\frac{\mathrm{NUE}}{\mathrm{CUE}} \cdot B_{C: N}$,

which yields $<20$ when NUE (nitrogen use efficiency) is taken as 1, CUE (carbon use efficiency) as 0.5, and $\mathrm{B}_{\mathrm{C}: \mathrm{N}}$ (biomass C:N ratio) as $<10$ (Kaiser et al. 2014). Such a value would suggest that saprotrophs decomposing plant residues are almost always $\mathrm{N}$ limited (Mooshammer et al. 2014). However, not all microbes are created equal, and $\mathrm{TER}_{\mathrm{C}: \mathrm{N}}$ may vary considerably across microbial types. In particular, there is reason 
to infer that saprotrophic cord-forming basidiomycete (CFB) fungi (Boddy 1999) - the physically largest and enzymatically most capable decomposers (De Boer et al. 2005; Šnajdr et al. 2011) - typically have their $\mathrm{N}$ needs met at substrate C:N ratios considerably higher than predicted from the equation above. Evidence includes the standard observation that $\mathrm{C}$ is selectively removed from decomposing litter (Lindahl et al. 2007), that CFB fungi apparently experience such selection pressure to surrender $\mathrm{N}$ in exchange for $\mathrm{C}$ that they evolved into mycorrhizae approximately 60 times independently (Martin et al. 2016), and that net $\mathrm{N}$ release from litter occurs once litter C:N falls below 40 (Parton et al. 2007). A few considerations may account for this. First, fungi can have biomass C:N ratios above 20 (Wallander et al. 2003; Strickland \& Rousk 2010), and CUE may be more reasonably estimated as closer to 0.3 (Sinsabaugh et al. 2013); with these two modifications, the equation above yields $T^{2} R_{\mathrm{C}: \mathrm{N}}$ higher than 65 for some fungi. Second, $\mathrm{N}$ may be recycled by the microbial community at different rates relative to $\mathrm{C}$ (Schimel \& Weintraub 2003; Kaiser et al.2014), depending on the availability of each, to effectively decouple C:N ratios of litter and dissolved organic matter (DOM) such that microbes in litter experience C:N stoichiometry very much in line with their collective optimum, and below the optima of certain fungi (Kaiseret al. 2014). Finally, the multicellular, mycelial growth form of CFB fungi may support internal N recycling, supported by the ability to translocate N (Boberg et al. 2010). Shoji et al. (2010) found that nuclei in basal hyphal cells were internally degraded and the resulting nutrients redistributed within the organism, enhancing biomass accumulation substantially under nutrient-starved conditions. Such autophagy combined with cytoplasmic translocation to active hyphal tips (Wallander et al. 2003) can lead to large tracts of vacuolated hyphae (Shoji et al. 2006) in basal interior parts of the mycelium, making these tissues increasingly structural (transport-focused 'cords') rather than metabolic, thereby raising their C:N ratios. Schimel's and Weintraub's (2003) model yields TER $\mathrm{C}_{\mathrm{N} \text { N }}$ values well above 65 when $\mathrm{N}$ recycling and biomass C:N are both high. New fungal biomass can potentially be synthesised using a combination of external substrate (plant litter), internal nutrients no longer needed for metabolism, and low C:N DOM. Combined, these factors may help explain how some CFB fungi can thrive on substrates with C:N ratios of 90 and beyond (Keiblinger et al.2010; Xiong et al. 2019). Taken together, it seems likely that under most circumstances, $\mathrm{C}$ is far more interesting to many CFB fungi than N. Conversely, with biomass C:N less than 5 (Strickland \& Rousk 2010) the equation above suggests that many bacteria likely have TER $_{\mathrm{C}: \mathrm{N}}$ values below C:N of plant residues and relatively N-rich DOM (Kaiser et al. 2014), placing them in a frequently N-limited condition.

\section{The importance of geometry: return on investment}

The very same property that may help reduce relative $\mathrm{N}$ requirements - the mycelial growth form - can also help explain the predominance of CFB fungi in the group of organisms responsible for oxidative exoenzyme production (Kirk \& Farrell 1987; De Boer et al. 2005). Decomposition that depends on oxidative enzymes, particularly peroxidases, is an energetically unpredictable process that has been previously characterised as "enzymatic combustion" (Kirk \& Farrell 1987). Because the process is non-specific and relies on chain-reactions generating reactive oxygen species (free radicals) (Hofrichter 2002; Brown \& Chang 2014), it brings two major challenges not associated with hydrolytic decomposition. First, a fraction of the targeted substrate is liable to fully mineralise without ever passing through a cell (Hofrichter et al. 1999) - this is the 'combustion' part - and, second, the aggressive free radical generation puts the decomposer at risk of self-induced oxidative stress (Hammel et al. 2002; Zhanget al. 2016), which may require costly defences. Alternatively, much of the strong oxidising activity could take place at somewhat of a physical distance, as with the manganese peroxidase system (Hofrichter 2002). Distant action via low molecular weight redox mediators may be doubly necessary on the nitrogenous substrates protected from proteolysis by bond occlusion or steric hindrance (Rillig et al.2007) thought to account for a substantial fraction of long-lived SOM (Knicker 2011). On a purely geometric basis, action at a distance increases the probability of decay products going to another organism than that which initiated decay (Fig. 1). Combined, the abovementioned challenges limit the net return on investment of oxidative decomposition, and more so for a unicellular decomposer than for its mycelial counterpart, as the greater interception area conferred by mycelial geometry reduces incidence of losing decay products to the competition (Fig. 1). This geometric advantage could plausibly shift oxidative decomposition from a net gain to a net loss under a range of circumstances. 


\section{Bacterial sociobiology}

We have argued that large fungi, by virtue of their size, are likely to have an advantage in oxidative decomposition and require less $\mathrm{N}$ from their substrate compared with single-celled bacteria. What about physically larger bacterial growth forms? Filamentous morphology, as inStreptomyces, and colonial growth, such as biofilms, can potentially bring the economics of oxidative enzyme investment closer to those of mycelial fungi.

In the former case a substantial gap remains in the attainable surface area compared with mycelial fungi, so that oxidative-economic parity remains unlikely. The latter case is evolutionarily nuanced. With respect to the bacterial colony, synthesis of oxidative enzymes into a substrate represents a type of 'public good' (Table 1). Within a colony, natural selection favours 'free riders' (phenotypes that enjoy the benefits of the public good without themselves contributing), and between colonies, natural selection favours altruistic investment in public goods (Nadell et al.2009). With a high degree of genetic relatedness within colonies, altruistic (Table 1) investments can evolve (West et al. 2006; Nadell et al. 2009), but cooperative outcomes are not guaranteed (de Vargas Roditi et al. 2013). As such, a potential competitive tension between individuals in a colony, largely absent between cells within a fungal individual, limits spatial resource-sharing within biofilms compared to mycelia. Crucially, the likelihood of cooperation depends on the cost to individuals of providing the public good in question (West et al. 2006; de Vargas Roditi et al. 2013). The capacity to regulate provision of a public good in response to its fitness cost, sometimes termed "metabolic prudence", is therefore the more evolutionarily stable and common strategy of co-operation among bacteria (de Vargas Roditi et al. 2013). In the case of oxidative exo-enzyme secretion, a clear inflection point in fitness cost may occur with N limitation: enzymes are proteins, with C:N lower than bacterial biomass (Schimel \& Weintraub 2003), such that their synthesis ought to incur greater fitness cost to an $\mathrm{N}$ limited bacterium than to a $\mathrm{C}$ limited bacterium. Co-operation between bacteria on enzymatic oxidative substrate mineralisation should be situational when $\mathrm{C}$ limited and very unlikely when $\mathrm{N}$ limited. That is, $\mathrm{N}$ limitation may undermine the evolutionary stability of the co-operation necessary for gainful oxidative decomposition by bacteria.

\section{The unexpected challenges of too much $N$}

The previous three sections lay the key foundation for our broader argument: that the capacity to oxidatively mineralise substrate tends to coincide with $\mathrm{C}$ limitation. With access to a range of different substrates, the greatest return on investment on such activity thus comes from targeting fresh plant residues, which are typically abundant, concentrated and $\mathrm{C}$ rich. This in turn imparts a large opportunity cost (Table 1) to investment in oxidative mineralisation of other, less concentrated and $\mathrm{C}$ rich substrates, such as nonhydrolysable low C:N substrates (NHLS). Here lies the first challenge of too much N: to the decomposers capable of targeting non-hydrolysable substrate, it displaces the more valuable element (C). Seen through an evolutionary lens, those fungi who invest a given quantity of resources in oxidatively decomposing plant residues will receive greater return, relative to their needs $(\mathrm{C})$, for building biomass and reproducing than those who invest the same resources in decaying NHLS, yielding a selection pressure against its decomposition. Only with intense competition between oxidisers for plant residues (despite substantial competition for other resources, such as space and water, from hydrolytic microbes) could the strategy of targeting NHLS for energy be endowed with frequency-dependent fitness (Table 1). The niche would remain sparsely inhabited, because its only advantage - avoiding costly competition - is lost when too many players participate.

So far, we have a scenario in which NHLS decomposes slowly and only under certain conditions. But even under these conditions, a second and game-changing challenge can arise from an overabundance of $\mathrm{N}$ in an oxidiser's substrate. If the oxidiser, say a CFB fungus, is reliant on action at a distance and a large interception area to capture decay return products, then smaller, fast-growing or motile bacteria can opportunistically compete for those return products in the space between decomposer and substrate (Lang et al. 1997; De Boer et al.2005)(Fig. 2). The fungus may employ antibiotic strategies (De Boeret al. 2005), but this imparts yet another cost to oxidative decomposition. A positive net return on investment in oxidative substrate mineralisation may be possible only if the capacity of opportunistic scavengers to grow and intercept $\mathrm{C}$ is limited by $\mathrm{N}$. If substrate C:N falls substantially below the TER $\mathrm{C}_{\mathrm{N}}$ of the opportunists, such that its decay liberates sufficient $\mathrm{N}$ to unshackle scavenging of $\mathrm{C}$, decomposition driven by oxidative 
exo-enzymes may become a net loss and cease entirely.

\section{The model}

Based on the logic above, we have developed a model to evaluate the outcomes for non-hydrolysable substrate across a range of C:N values (full description in Supplementary Materials). Our model is based on two linked hypotheses: (1) From an evolutionary point of view, microbes should optimise their enzyme production $(E)$ to maximise the net fitness gain $(F)$, and they should only decompose NHLS if the uptake of decomposition products $(S)$ brings a net fitness gain $(F>0)$ in terms of growth minus costs of enzyme production $(E$ ). (2) $F$ strongly depends on the fraction of decomposition products absorbed by the decomposer $(f$ u), i.e. the return on investment, which depends on the distance to the substrate and the competition from opportunistic bacteria. A minimum 'safe' distance for oxidative decomposition is included, based on the idea that cost of oxidative stress to the decomposer will surpass potential gain from decomposition when the activity is too close.

The production of $S$ (the decomposition rate) is a saturating function of enzyme production. $S=\frac{\mathrm{q} d_{E} \mathrm{E}}{d_{E} E+1}$, where $q=$ substrate quality, and $d_{\mathrm{E}}=$ enzyme efficiency. The use of decomposition products for growth is further limited by $f_{\mathrm{u}}$ and the carbon use efficiency $(e)$. The minimum $f_{\mathrm{u}}$ that allows decomposition $(f$ u $\min$ ) is given by the equation:

$F=$ growth - enzyme costs $=\frac{\mathrm{q} d_{E} \mathrm{E}}{d_{E} E+1}$ e $f_{u}-E>0$, which implies that $f_{\mathrm{u} \min }=\frac{1}{\mathrm{q} d_{\mathrm{E}} \mathrm{e}}$.

While $e, d_{\mathrm{E}}$ and $q$ are relatively constant for a given substrate, $f_{\mathrm{u}}$ is highly variable depending on the distance $(d)$ between decomposer and substrate. $f_{\mathrm{u}}$ is modelled as the product of three probabilities: $f_{u}=p_{1} \bullet p_{2} \bullet p_{3}$, where $p_{1}=$ the probability that $S$ diffuses the distance $d$ to the decomposer without getting absorbed by an opportunist bacteria in the soil, $p_{2}=$ the probability that $S$ hits the decomposer after diffusing a distance $d, p_{3}=$ the probability that $S$ is not absorbed by bacteria on the surface (hyphae) of the decomposer.

Diffusion is modelled as a random walk process (Fig. 2a), which implies that $p_{1}$ decreases with $d$ and the expected number of bacterial-sized soil volumes passed while diffusing through the soil. $p_{1}$ also depends on bacterial uptake capacity, which is reduced by substrate $\mathrm{C}: \mathrm{N}$ ratios $\left(\mathrm{C}: \mathrm{N}_{\mathrm{s}}\right)$ that limit bacterial growth, i.e. if $\frac{C: N_{b}}{C: N_{s}}<e$, where $C: N_{b}=$ bacterial biomass C:N ratio. For geometrical reasons, $p_{2}$ increases with the size of the decomposer and decreases with $d$ (Fig. 2b). $p_{3}$ is calculated as the expected fraction of hyphal surface area not covered by bacteria, assuming that the bacteria are randomly distributed on the hyphae.

Microbial population densities and parameters were estimated based on observations in forest soils. However, given the lack of quantitative observations of these micro-scale process, the purpose of this analysis is not to quantify the impact of these effects in a particular soil, but rather to test the plausibility of spatially dependent competition as a mechanism that limits, or even prevents, decomposition of NHLS.

Results

We evaluated the fraction $\left(f_{\mathrm{u}}\right)$ of decomposition products taken up and how it depends on the distance between decomposer and substrate $(d)$, and on the substrate C:N ratio. We found that the maximum $d$ that allows decomposition $\left(d_{\max }\right)$ is smaller for low $\mathrm{C}: \mathrm{N}$ substrate that induce bacterial $\mathrm{C}$ limitation than for higher C:N substrates (Fig. 3). This effect is due to the stronger bacterial competition with the C limited fungus when bacteria also are $\mathrm{C}$ limited. $d_{\max }$ for a fungus increases with substrate C:N, resulting in an increased volume of soil explored per hyphae (Fig. 4) and implying a much higher decomposition rate for non-hydrolysable substrates with high C:N than with low C:N.

If $d \max _{\text {max }}$ smaller than the safe distance for oxidative decomposition $\left(d_{\mathrm{s}}\right)$, the substrate will not be decomposed, which is more likely to happen for low C:N substrates (Fig. 3). Analogously, if $d$ max is smaller than the necessary distance for decomposition imposed by physical or chemical constraints, such as bond occlusion or steric hindrance, the substrate will not be decomposed. 
For a single decomposing bacterium, $f_{\mathrm{u}}$ is much smaller than for a fungus due to small size (green line in Fig. 3). Substrate C:N has only a negligible effect on $f_{\mathrm{u}}$ for such bacterial decomposers (not shown). Consequently, $d$ max for bacterial decomposition of NHLS is very small, probably smaller than any reasonable $d_{\mathrm{s}}$, which would imply that free-living bacteria will not decompose NHLS.

\section{Conclusions}

Taken together, the evolutionary and ecological considerations outlined and modelled above help us see how, hypothetically, non-hydrolysable low C:N substrate can be largely spared decomposition and accumulate (Fig. 5).

For hydrolysable substrates, our view is indistinguishable from existing perspectives on SOM dynamics: organic matter will accumulate only when it is physically or chemically protected from microbial access. Here we agree that important factors allowing for SOM protection include such things as adsorption to surfaceactive clays and occlusion within aggregates whose pores are too small for microbial ingress (Cotrufoet al. 2013). It is with regard to non-hydrolysable substrates that our hypothesis can contribute a novel perspective. Here, in the non-hydrolysable world, we argue that the most important factor in fact is C:N stoichiometry: when it is sufficiently low, physical and chemical protection are no longer necessary to explain organic matter persistence. Including this component - we could call it GEO inhibition (inhibition of decomposition due to Geometric Ecology of Oxidation) - in the SOM conceptual model provides an alternate explanation for a wide range of responses, enabling targeted experiments that can adjudicate between alternative mechanistic hypotheses.

For example, GEO inhibition can explain why so much of SOM resembles peptides and proteins (Knicker 2011) and microbial residues (Kallenbachet al. 2016) even though stabilisation mechanisms such as aggregation and mineral binding ought to act also on many high C:N plant residues (Cotrufo et al. 2013) (Fig. 6). Our framework also provides an additional mechanism to explain both $\mathrm{N}$ fertilisation (Bonneret al. 2019) and priming (Kuzyakov et al. 2000) effects, unifying them as opposite ends of one spectrum. Although added $\mathrm{N}$ will likely be taken up by cellulolytic bacteria and yeasts and enable them to acquire more $\mathrm{C}$ hydrolytically, at sufficiently large rates it ought to partially lessen N limitation of opportunistic scavengers, imposing additional costs to oxidative decomposition and thereby suppressing it under otherwise barely favourable conditions. It is indeed only at high $\mathrm{N}$ rates and in cold climates (oxidative enzymes typically have temperature optima close to $40 \mathrm{C}$ ) that this effect is typical (Bonneret al. 2019). Conversely, large addition of labile $\mathrm{C}$ causes all but the most C-limited (CFB fungi) to run into N-limitation, leaving CFB fungi with greater biomass and relatively lower competition, increasing oxidative decomposition and thereby substrate turnover, resulting in a priming effect.

In addition to predictions already consistent with prior observation, such as high peptide content in SOM and the priming effect, our model makes falsifiable predictions that contrast with those of existing hypotheses. Broadly speaking, existing hypotheses posit that a CFB fungus limits peroxidase activity targeting persistent, low $\mathrm{C} / \mathrm{N}$ SOM in its vicinity because the activity will be ineffective on the physically or chemically protected substrate, and the investment will be wasteful. Our hypothesis posits that the activity will indeed be effective, but the fungus will nevertheless receive little return on investment, so the investment will be wasteful. It follows that if peroxidase activity is manipulated, either through direct and judicious artificial supply (perhaps with a microdialysis probe) or over-expressing CFB fungus mutants, existing hypotheses predict a less fit fungus and largely unaffected low $\mathrm{C} / \mathrm{N}$ SOM, whereas our hypothesis predicts a less fit fungus and a transfer of organic matter from low $\mathrm{C} / \mathrm{N}$ SOM to bacterial biomass.

\section{Final words}

We have argued that decomposition of non-hydrolysable low C:N substrate is ecologically constrained in mycelial fungi, evolutionarily constrained in co-operating bacteria, and geometrically constrained in unicellular microbes. As such, there is much in SOM that can be mineralised but is not, because for those microbes with such abilities, it is often maladaptive. In other words, those who can don't want to, and those who want to can't. 


\section{Acknowledgements}

We would like to acknowledge the many very useful discussions, usually over coffee, with colleagues, friends and family, that helped clarify and crystallise our thoughts for this article. We would like to thank The Knut and Alice Wallenberg Foundation (\#2015.0047 and Future Silviculture) and The Kempe Foundations for support.

\section{References}

Boberg, J.B., Finlay, R.D., Stenlid, J. \& Lindahl, B.D. (2010). Fungal C translocation restricts Nmineralization in heterogeneous environments. Funct. Ecol. , 24, 454-459.

Boddy, L. (1999). Saprotrophic cord-forming fungi: Meeting the challenge of heterogeneous environments. In: Mycologia . pp. 13-32.

Bonner, M.TL., Castro, D., Schneider, A.N., Sundström, G., Hurry, V., Street, N.R., et al. (2019). Why does nitrogen addition to forest soils inhibit decomposition? Soil Biol. Biochem. , 137, 107570.

Brown, M.E. \& Chang, M.C.Y. (2014). Exploring bacterial lignin degradation. Curr. Opin. Chem. Biol. , $19,1-7$.

Cotrufo, M.F., Wallenstein, M.D., Boot, C.M., Denef, K. \& Paul, E.A. (2013). The Microbial EfficiencyMatrix Stabilization (MEMS) framework integrates plant litter decomposition with soil organic matter stabilization: do labile plant inputs form stable soil organic matter?Glob. Change Biol. , 19, 988-995.

De Boer, W., Folman, L.B., Summerbell, R.C. \& Boddy, L. (2005). Living in a fungal world: impact of fungi on soil bacterial niche development.FEMS Microbiol. Rev. , 29, 795-811.

Hammel, K., Kapich, A., Jensen, K.A. \& Ryan, Z.C. (2002). Reactive oxygen species as agents of wood decay by fungi. Enzyme Microb. Technol. , 30, 445-453.

Hofrichter, M. (2002). Review: Lignin conversion by manganese peroxidase (MnP). Enzyme Microb. Technol. , 30, 454-466.

Hofrichter, M., Scheibner, K., Bublitz, F., Schneegaß, I., Ziegenhagen, D., Martens, R., et al. (1999). Depolymerization of Straw Lignin by Manganese Peroxidase from Nematoloma frowardii is Accompanied by Release of Carbon Dioxide. Holzforschung , 53, 161-166.

Kaiser, C., Franklin, O., Dieckmann, U. \& Richter, A. (2014). Microbial community dynamics alleviate stoichiometric constraints during litter decay. Ecol. Lett. , 17, 680-690.

Kallenbach, C.M., Grandy, A.S. \& Frey, S.D. (2016). Direct evidence for microbial-derived soil organic matter formation and its ecophysiological controls. Nat. Commun. , 7:13630, 1-10.

Keiblinger, K.M., Hall, E.K., Wanek, W., Szukics, U., Hämmerle, I., Ellersdorfer, G., et al. (2010). The effect of resource quantity and resource stoichiometry on microbial carbon-use-efficiency.FEMS Microbiol. Ecol. , $73,430-440$.

Kirk, T.K. \& Farrell, R.L. (1987). Enzymatic "Combustion": The Microbial Degradation of Lignin. Annu. Rev. Microbiol. , 41, 465-501.

Knicker, H. (2011). Soil organic N - An under-rated player for C sequestration in soils? Soil Biol. Biochem. , 43, 1118-1129.

Kuzyakov, Y., Friedel, J.K. \& Stahr, K. (2000). Review of mechanisms and quantification of priming effects. Soil Biol. Biochem., 32, 1485-1498.

Lal, R. (2014). Societal value of soil carbon. J. Soil Water Conserv. , 69, 186A-192A.

Lang, E., Kleeberg, I. \& Zadrazil, F. (1997). Competition of Pleurotus sp. and Dichomitus squalens with soil microorganisms during lignocellulose decomposition. Bioresour. Technol. , 60, 95-99. 
Lindahl, B.D., Ihrmark, K., Boberg, J., Trumbore, S.E., Högberg, P., Stenlid, J., et al. (2007). Spatial separation of litter decomposition and mycorrhizal nitrogen uptake in a boreal forest.New Phytol. , 173, $611-20$.

Martin, F., Kohler, A., Murat, C., Veneault-Fourrey, C. \& Hibbett, D.S. (2016). Unearthing the roots of ectomycorrhizal symbioses. Nat. Rev. Microbiol. , 14, 760-773.

Mooshammer, M., Wanek, W., Zechmeister-Boltenstern, S. \& Richter, A.A. (2014). Stoichiometric imbalances between terrestrial decomposer communities and their resources: mechanisms and implications of microbial adaptations to their resources. Front. Microbiol., 5.

Nadell, C.D., Xavier, J.B. \& Foster, K.R. (2009). The sociobiology of biofilms. FEMS Microbiol. Rev. , 33, 206-224.

Parton, W., Silver, W.L., Burke, I.C., Grassens, L., Harmon, M.E., Currie, W.S., et al. (2007). Global-Scale Similarities in Nitrogen Release Patterns During Long-Term Decomposition.Science, 315, 361-364.

Rillig, M.C., Caldwell, B.A., Wösten, H.A.B., Sollins, P. \& Wo, H.A.B. (2007). Role of proteins in soil carbon and nitrogen storage: controls on persistence. Biogeochemistry , 85, 25-44.

Schimel, J.P. \& Weintraub, M.N. (2003). The implications of exoenzyme activity on microbial carbon and nitrogen limitation in soil: a theoretical model. Soil Biol. Biochem. , 35, 549-563.

Schmidt, M.W.I., Torn, M.S., Abiven, S., Dittmar, T., Guggenberger, G., Janssens, I.A., et al. (2011). Persistence of soil organic matter as an ecosystem property. Nature , 478, 49-56.

Shoji, J., Arioka, M. \& Kitamoto, K. (2006). Vacuolar Membrane Dynamics in the Filamentous Fungus Aspergillus oryzae. Eukaryot. Cell , 5, 411-421.

Shoji, J., Kikuma, T., Arioka, M. \& Kitamoto, K. (2010). Macroautophagy-Mediated Degradation of Whole Nuclei in the Filamentous Fungus Aspergillus oryzae. PLOS ONE , 5, e15650.

Sinsabaugh, R.L., Manzoni, S., Moorhead, D.L. \& Richter, A. (2013). Carbon use efficiency of microbial communities: stoichiometry, methodology and modelling. Ecol. Lett. , 16, 930-939.

Šnajdr, J., Dobiášová, P., Větrovský, T., Valášková, V., Alawi, A., Boddy, L., et al. (2011). Saprotrophic basidiomycete mycelia and their interspecific interactions affect the spatial distribution of extracellular enzymes in soil. FEMS Microbiol. Ecol. , 78, 80-90.

Strickland, M.S. \& Rousk, J. (2010). Considering fungal: Bacterial dominance in soils - Methods, controls, and ecosystem implications. Soil Biol. Biochem. , 42, 1385-1395.

de Vargas Roditi, L., Boyle, K.E. \& Xavier, J.B. (2013). Multilevel selection analysis of a microbial social trait. Mol. Syst. Biol. , 9, 684 .

Wallander, H., Nilsson, L.O., Hagerberg, D. \& Rosengren, U. (2003). Direct estimates of C:N ratios of ectomycorrhizal mycelia collected from Norway spruce forest soils. Soil Biol. Biochem. , 35, 997-999.

West, S.A., Griffin, A.S., Gardner, A. \& Diggle, S.P. (2006). Social evolution theory for microorganisms. Nat. Rev. Microbiol. , 4, 597-607.

Xiong, S., Martín, C., Eilertsen, L., Wei, M., Myronycheva, O., Larsson, S.H., et al. (2019). Energy-efficient substrate pasteurisation for combined production of shiitake mushroom (Lentinula edodes) and bioethanol. Bioresour. Technol. , 274, 65-72.

Zhang, J., Presley, G.N., Hammel, K.E., Ryu, J.-S., Menke, J.R., Figueroa, M., et al. (2016). Localizing gene regulation reveals a staggered wood decay mechanism for the brown rot fungus Postia placenta.Proc. Natl. Acad. Sci. U. S. A., 113, 201608454.

Tables and figures 
Table 1. Definitions of terms from economics and evolutionary science used in this article

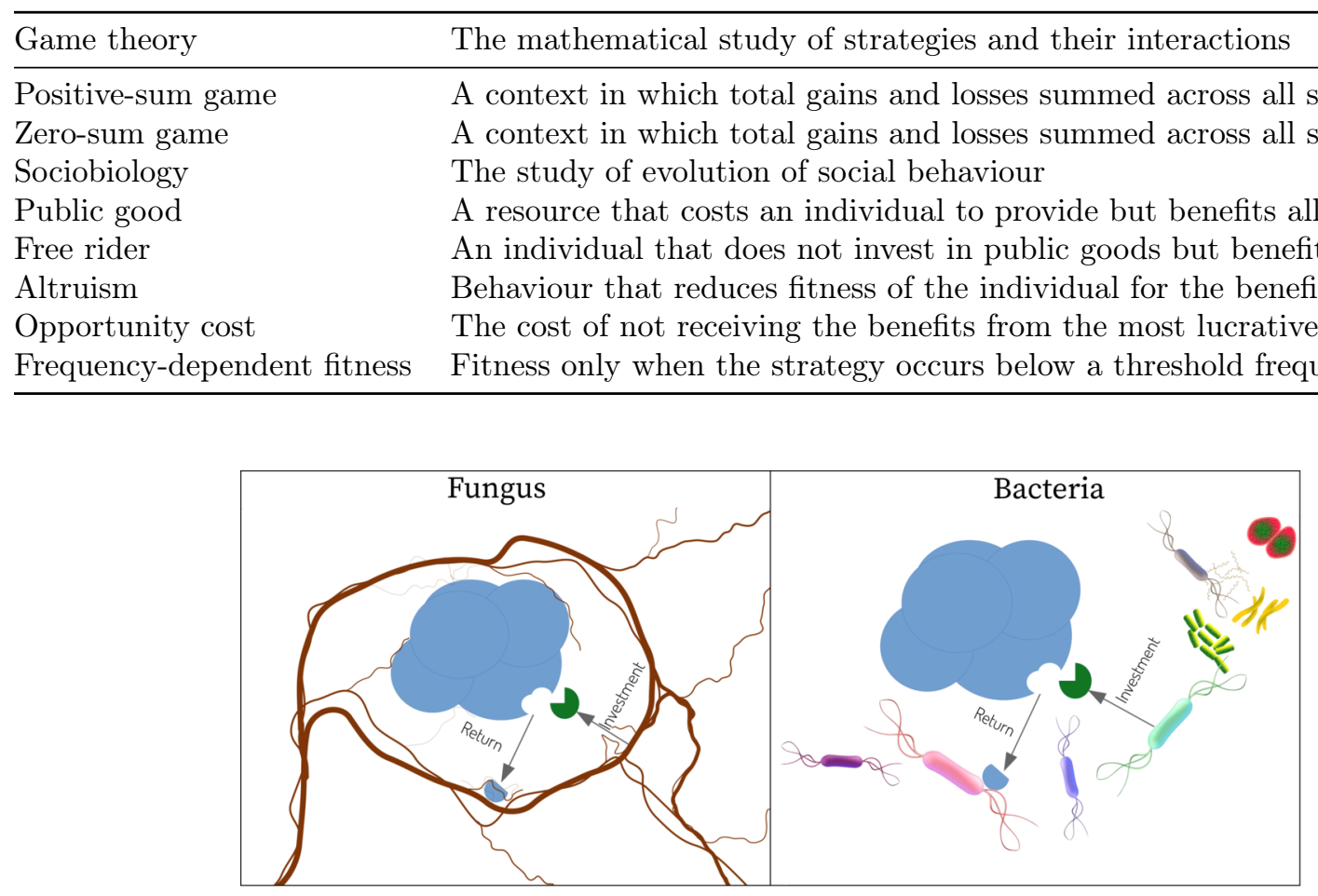

Fig. 1. Return on investment from oxidative enzyme activity, which often needs to occur at greater distance than hydrolytic enzyme activity, because of such limitations as bond occlusion, steric hindrance, or the need to avoid oxidative stress. We argue, geometrically, that a mycelial fungus has a stronger chance of intercepting return from its investment than a unicellular bacterium.

a

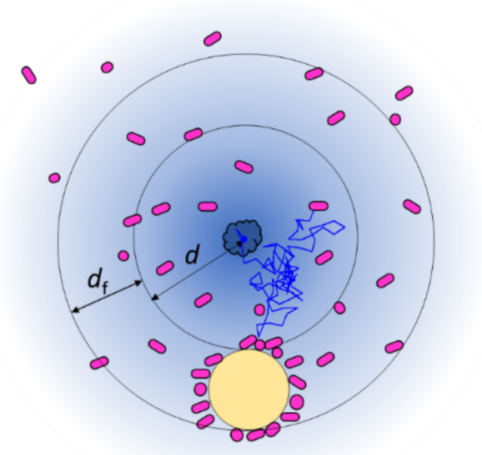

b

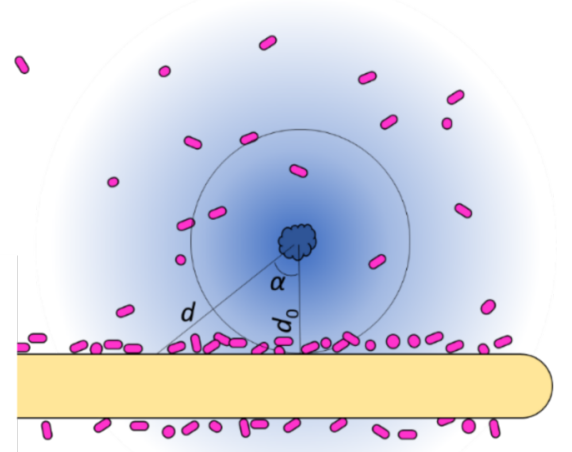

Fig. 2. Spatial geometry of decomposition: fungus (yellow) in 2D-cross sectional view (a ) and from the side (b ). Decomposing substrate at the centre (dark blue), concentration of decomposition products $(S$, blue shading), and bacteria (purple ovals) in the soil and on the fungal hyphae. The blue line in ashows an example of a path taken by a molecule of $S$. (b ) The distance from decomposition to the fungus $(d)$ depends on the angle $(\alpha)$ to the fungus. $d_{\mathrm{f}}=$ fungal diameter. 


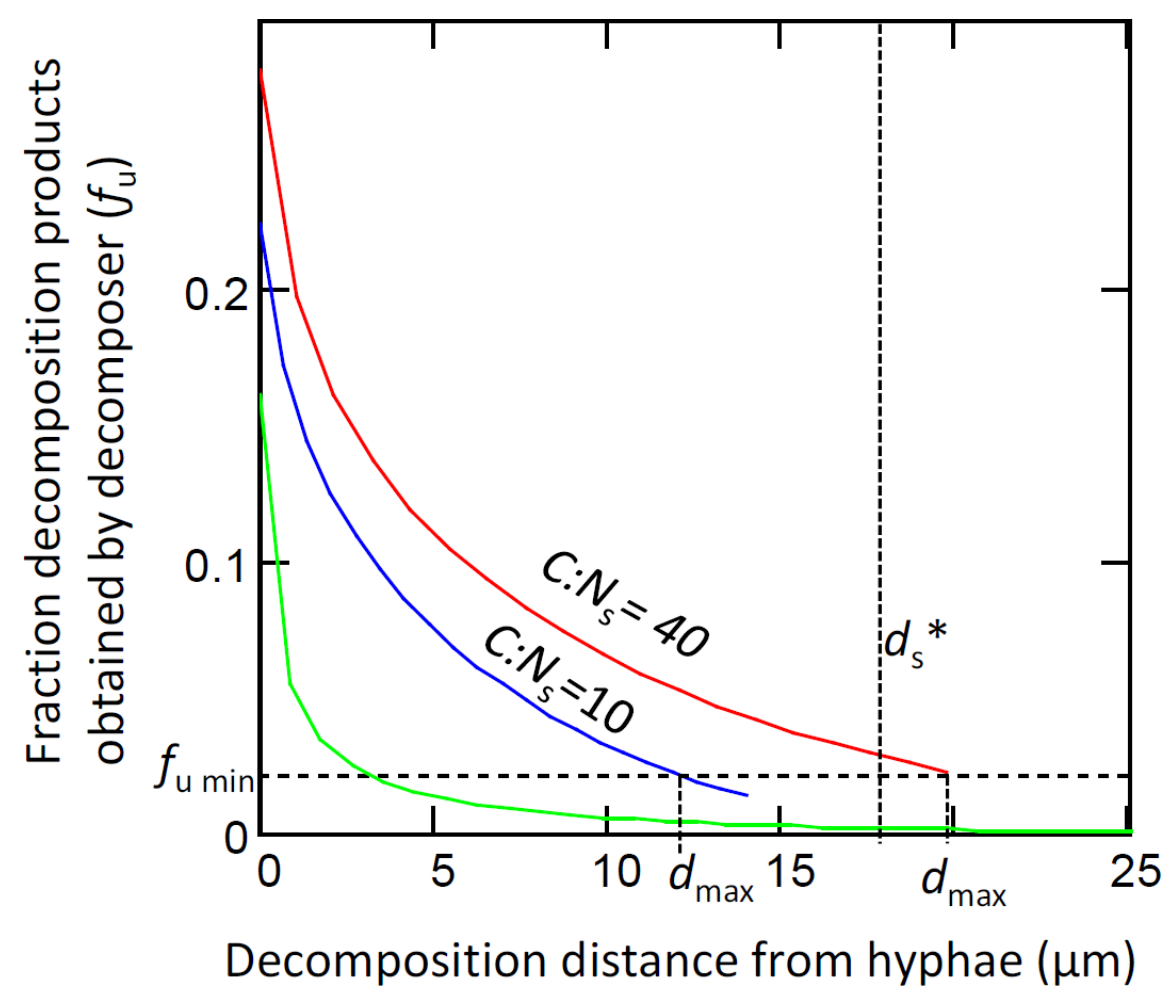

Fig. 3. The fraction of decomposition products absorbed by a decomposer fungus as a function of distance. Low C:N substrate (blue line) induces bacterial $\mathrm{C}$ limitation and high C:N substrate induces bacterial $\mathrm{N}$ limitation (red line). The green line shows $f_{\mathrm{u}}$ for a hypothetical decomposing bacterium (for $\mathrm{C}: \mathrm{N}_{\mathrm{s}}=20$ ). $f$ $\mathrm{u}$ min is the minimumf $\mathrm{u}$ that allows decomposition of the substrate. $d$ max is the maximum distances from the hyphae at which substrate will be decomposed. $d_{\mathrm{s}}{ }^{*}$ is a hypothetical value for the safe (or chemically necessary) distance for oxidative decomposition. Substrates with $d \max _{2}<d_{\mathrm{s}}{ }^{*}$ (blue and green lines) will not be decomposed. 


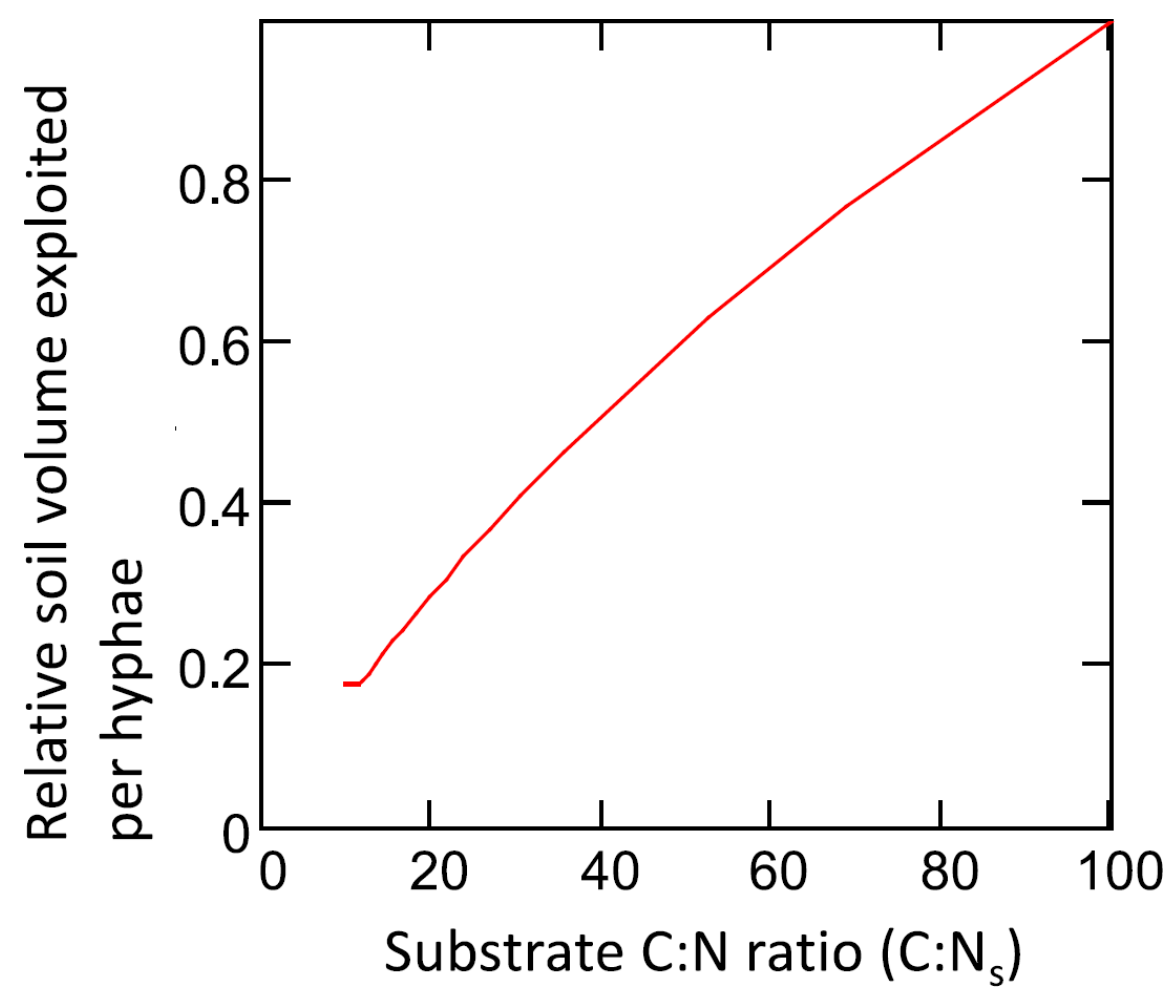

Fig. 4. The effect of substrate C:N ratio on the spatial extent of decomposition: the volume around a hypha within which substrate will be decomposed increases with substrate C:N ratio (based ond max, Fig. 3 ). The y-axis represents a measure of how much substrate that can be decomposed per hypha (relative to the volume at $\left.\mathrm{C}: \mathrm{N}_{\mathrm{s}}=100\right)$

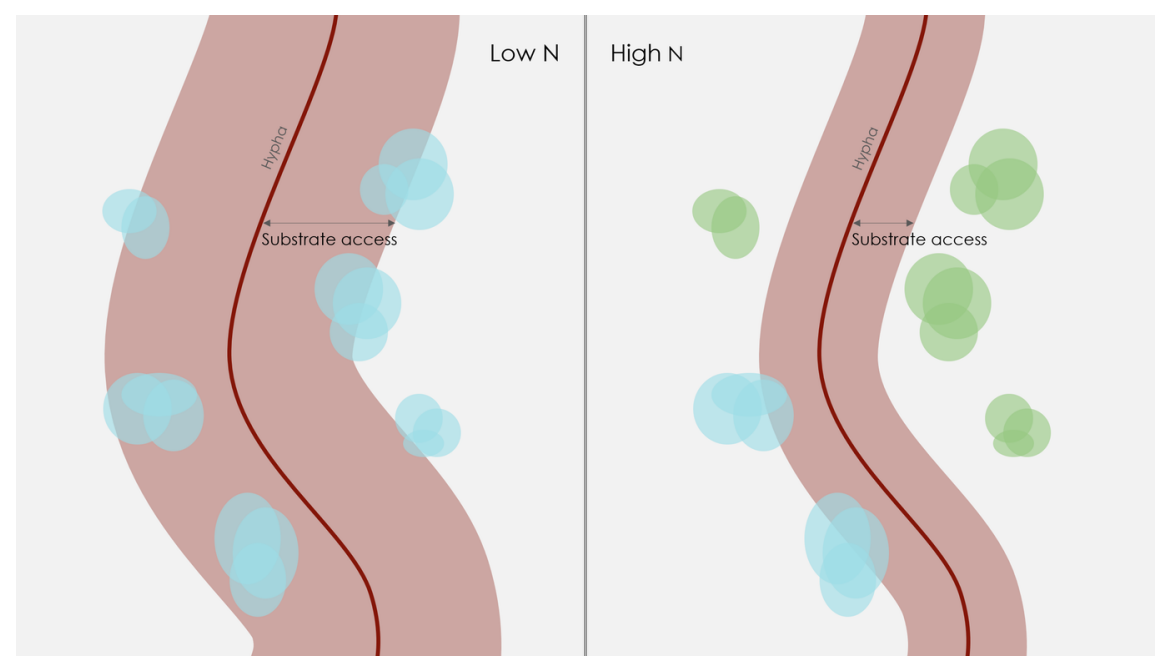

Fig. 5. Conceptual representation of the importance of $\mathrm{N}$ content of non-hydrolysable substrates. Low $\mathrm{N}$ substrates can be decayed at greater distance because bacterial scavenging of decomposition products is limited by $\mathrm{N}$ availability. When decomposition products provide sufficient $\mathrm{N}$ to fully unleash opportunistic scavenging of $\mathrm{C}$, the maximum distance at which non-hydrolysable substrates can gainfully be decomposed 
for $\mathrm{C}$ is diminished, resulting in substrates remaining intact (blue and green balloons represent accessed and unaccessed substrates, respectively).

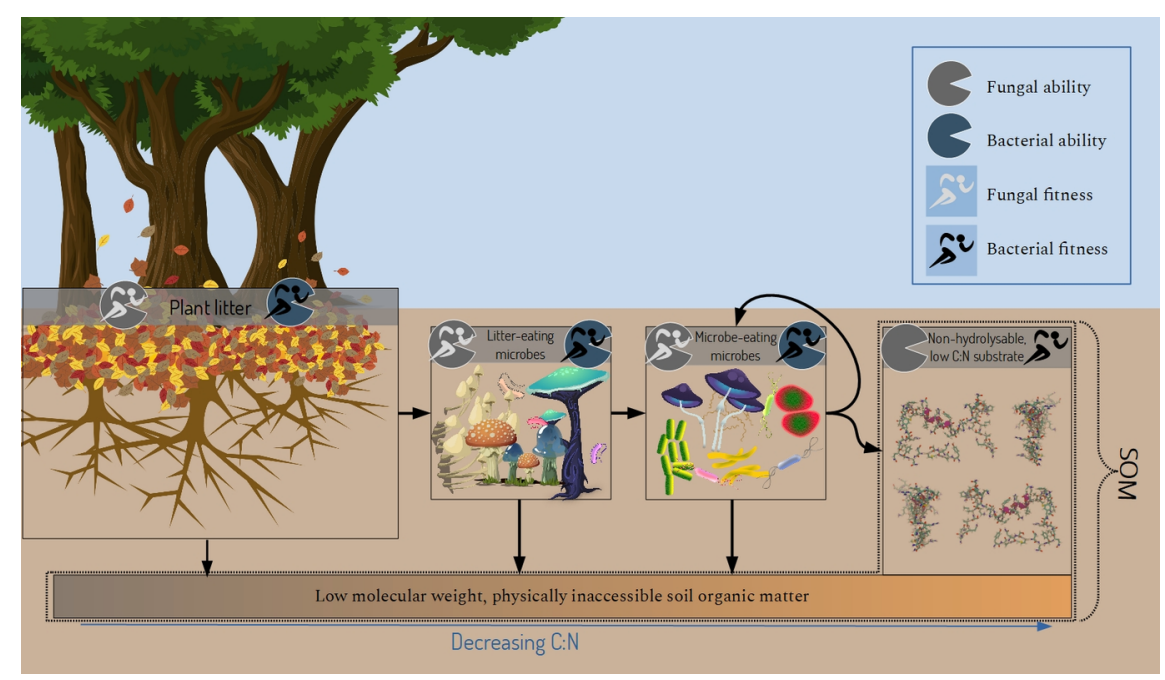

Fig. 6. Overview of SOM pool and the hypothesised contribution by preservation of non-hydrolysable, low C:N substrate. In our conceptualisation, a substrate will be decomposed, with minor fractions becoming physically and chemically protected by association with mineral soil, if and only if microbial 'ability' (chemical capacity to decay the substrate) and 'fitness' (net fitness conferred by decaying the substrate) intersect. Decomposition of non-hydrolysable low C:N substrate is fit but not possible for bacteria, and possible but not fit for fungi, resulting in a pool of SOM that is protected in spite of physical and chemical access.

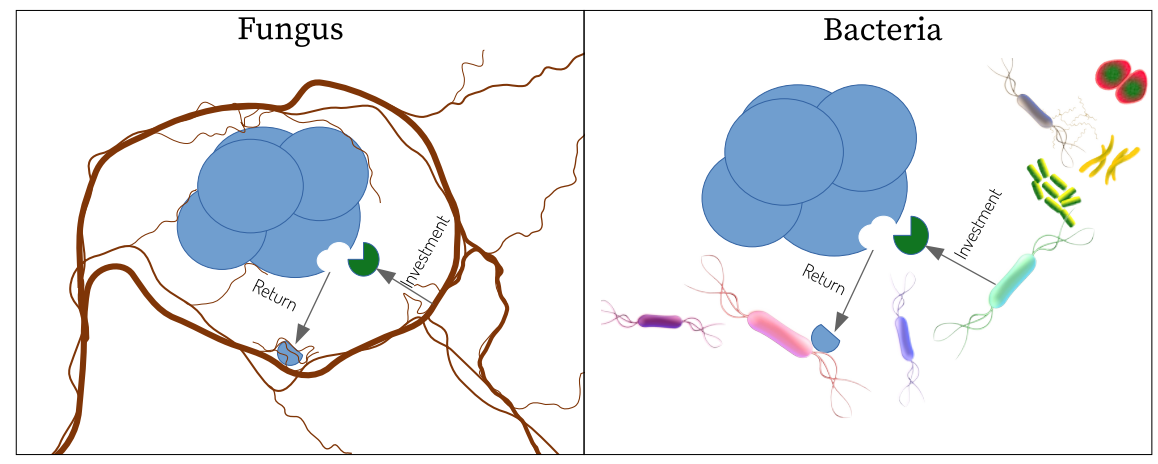


a

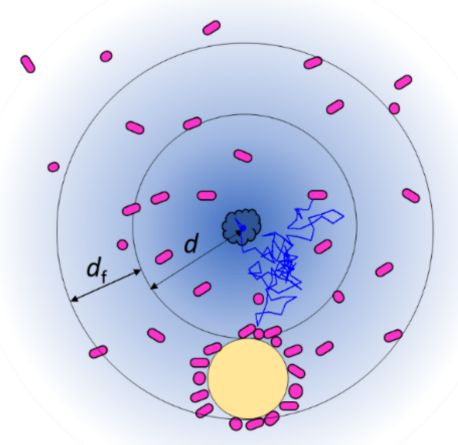

b

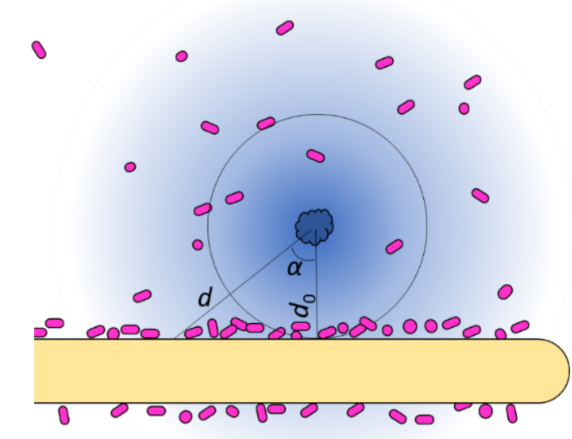

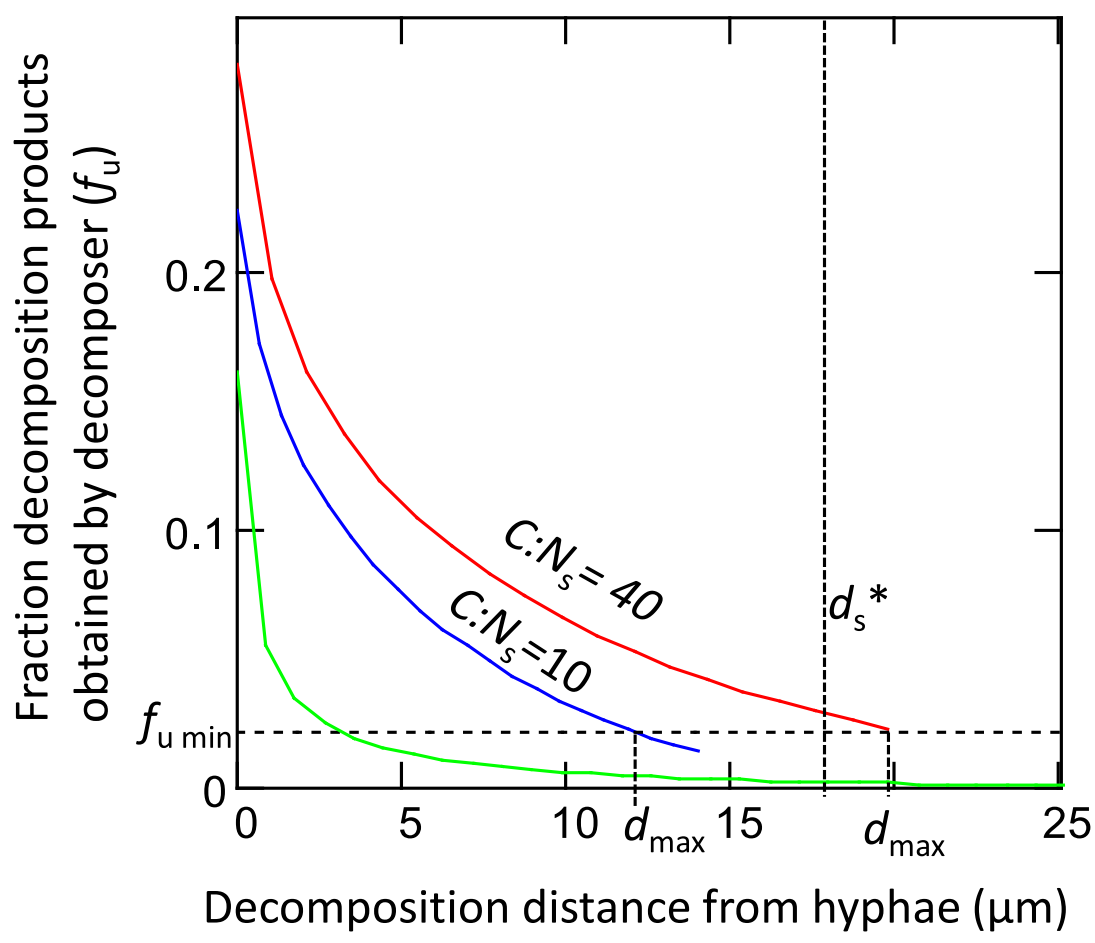



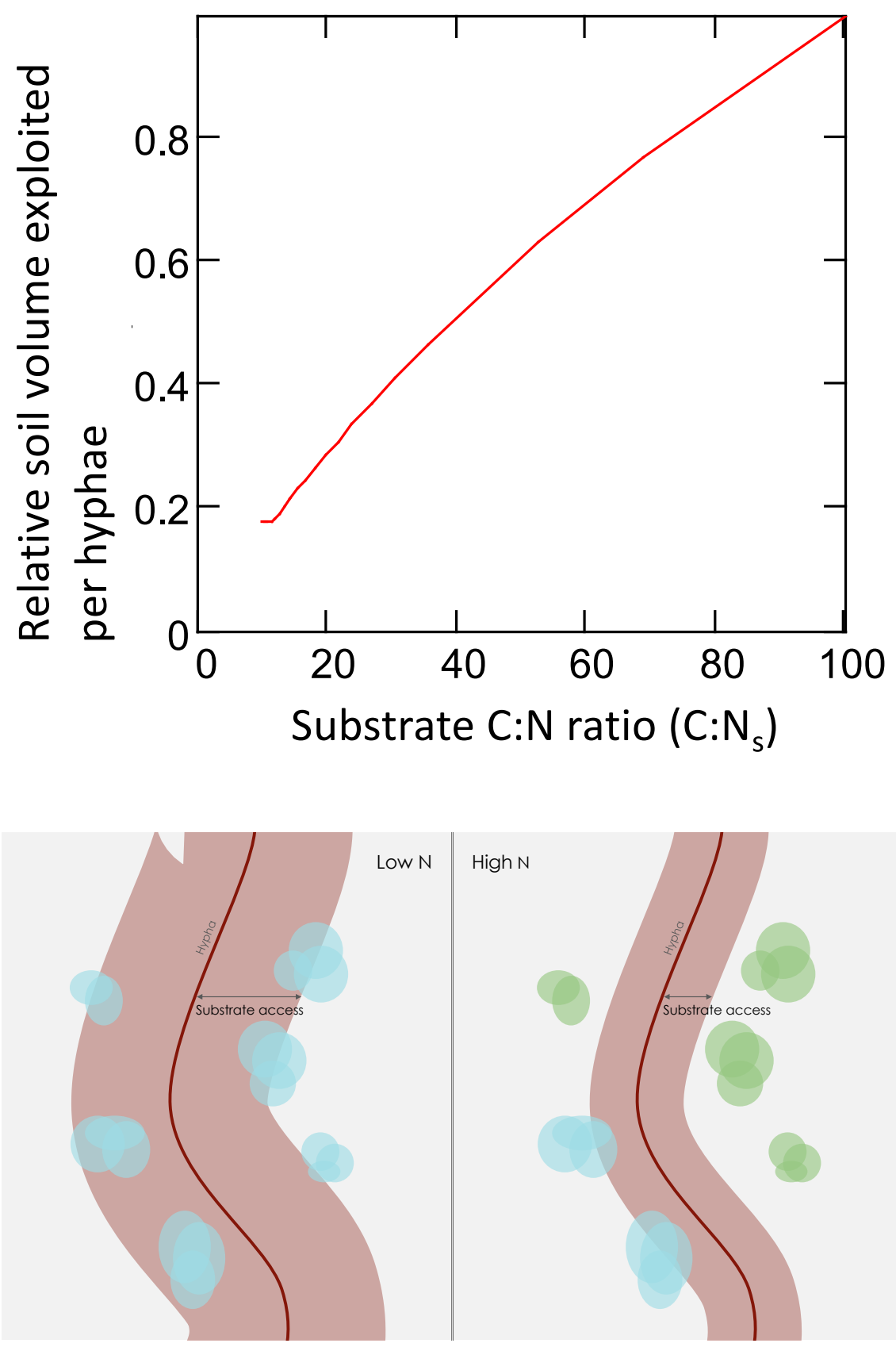


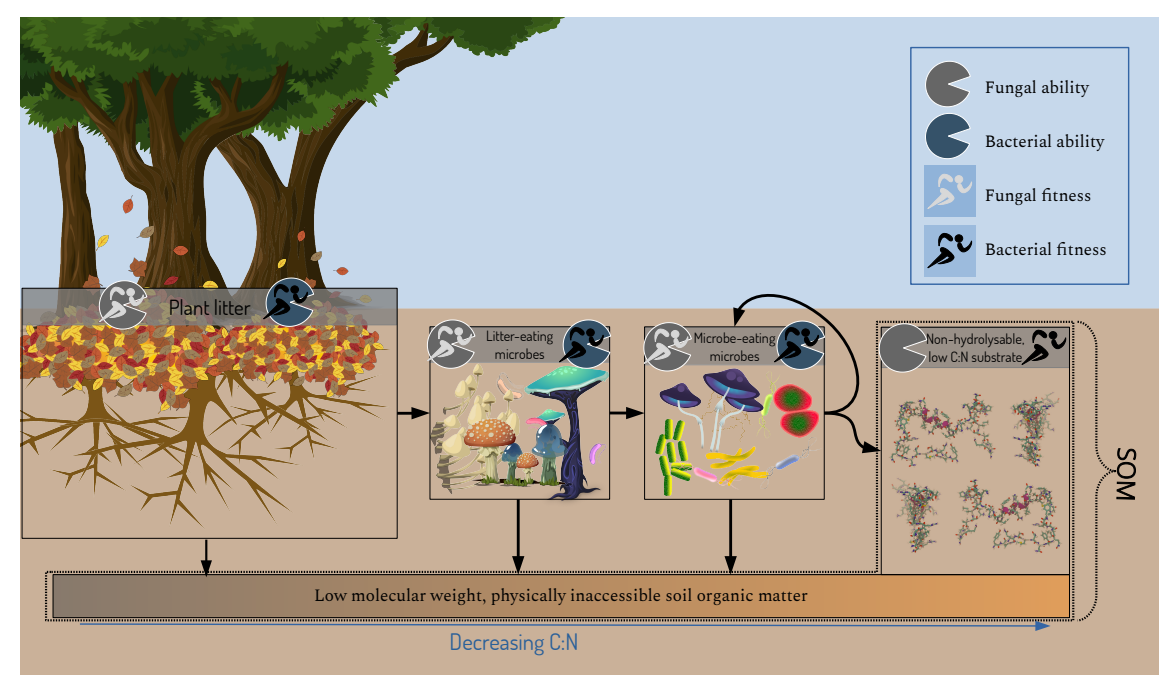

